\title{
IMPORTÂNCIA FISIOLÓGICA E TERAPÊUTICA DOS DERIVADOS NUCLEOPROTEÍDICOS $\left({ }^{\star}\right)$ \\ HENRIQUE TASTALDI \\ Catedrático, de Química Biológica da Faculdade de Farmácia e Odontologia dè S. Paulo
}

Nucleoproteidos são proteinas existentes nos núcleos, daí a sua denominação, e cujo brupo prostético é o ácido nucleico.

Em meiados do século passado, preocupava os primeiros bioquíminicos o estudo das fórmas orgânicas do fósforo. Para se aquilatar da importância que se dava aos biocompostos fosforados basta citar o aforisma insistente da época: "Ohne Phosphor keine Gedanke".

Hoppe Seyler incumbiu seu discípulo Miescher para realizar pesquisas no terreno em questão. Em 1868 Miescher submeteu à digestão cloridro-péptica pús obtido na clínica cirúrgica de Tübingen. Obteve un residuo inatacavel pelo suco gástrico e que imaginou fosse representado pelos núcleos. Deu a esta massa o nome de Nucleina.

Substância semelhante foi obtida mais tarde por Hioppe SEyler, do levedo (1871), por Kossel, de hemácias de aves (1881), e por Miescher e Schmiedeberg, de esperma de peixes (1896-1900). Verificou-se porém que a nucleina ainda era uma proteina conjugada mas que pela digestão tríptica perdia completamente as características proteicas, ficando um resíduo ácido, resistente à ação enzimática. Era o ' ardadeiro núcleo prostético do proteido original e ao qual MIESCHER deu o nome de Nucleina livre de proteina.

Em 1887, Altmann deu-lhe a denominação de ácido nucleico, conservada até nossos dias.

Obtido o ácido nucleico em quantidades apreciáveis, a partir de material rico em núcleos, especialmente levedo e timo, procurou-se logo conhecer sua composição química.

Tossel, em 1891, hidrolisando o ácido nucleico, poude isolar alguns componentes característicos, isto é, as bases nitrogenadas púricas e pirimidicas, que se vieram juntar aos outros componentes o ácido fosfórico e uma pentose.

Verificou-se depois que esta última era a $d$-ribose ou a $d$-2-ribodesose, ambas de tipo furânico, a primeira encontrada nos ácidos nucleicos de origem vegetal e a segunda nos de origem animal. Esta, por ter sido encontrada no ácido timonucleico, o ácido nuclèico animal mais estudado, recebeu tambem o nome de timinose.

(*) Palestra realizada em -19-6-42 no I. Biológico. 
O critério de diferenciação química dos ácidos nucleicos vegetais e animais é falho. porquanto já se obtiveram ácidos nucleicos animais con ribose. e ácidos nucleicos vegetais com ribodesose. Provavelmente existem ácidos nucleicos que em lugar da ribose contêm uma hexose, visto que na vicina, nucleósido vegetal, figura a d-glicose.<smiles>O=CC(O)C(O)C(O)COI</smiles>

d-ribose<smiles>OCC1C[IH]OC[C@@H]1CO</smiles>

d-2-ribodesose

A d-ribose faz parte tamben de outras substâncias de grande valor biológico, como a riboflavina (Vitamina B2) e o fermento amarelo de WARBuRg e Christian (1).

As bases pirimídicas, são: a uracila (2,6-dioxi-pirimidina), a timina (2,6-dioxi-5-metil-pirimidina) e a citosina (Z-oxi-6-amino-pirimidina ).<smiles>c1ccnnc1</smiles>

Pirimidina<smiles>O=c1ccc(=O)[nH][nH]1</smiles>

Uracila<smiles></smiles>

Timina<smiles>Nc1cc[nH]c(=O)n1</smiles>

Citosina

A uracila é encontrada nos ácidos nucleicos vegetais, e segundo uns, seria um produto artificial, formado pela desaminação oxidativa ou hidrolítica da citosina ( 1 a ). A timina é encontrada nos ácidos animais, dos quais o ácido timonucleico é o representante típico. A citosina existe em todos os ácidos nucleicos. Outras bases pirimídicas acham-se espalhadas na natureza, entre elas a metilcitosina (2-oxi-5metil-6-amino-pirimidina) e a alo-xana (2-4-5-6-tetra-oxi-pirimidina), que assumem importância especial pelo fato de figurarem na estrutura de vitaminas.<smiles>[CH]c1c[nH]c(=O)nc1N</smiles>

Metil-citosina<smiles>O=C1NC(=O)C(=O)N1</smiles>

Aloxana 
A porção pirimídica da tiamina e da sua fórma ativa - a cocarboxilase - apresenta grande semelhança com a metil-citosina. A cocarboxilase age como catalisador na descarboxilação do ácido pirúvico, desempenhando assim um papel decisivo no metabolismo intermediário dos glícidos e na fermentação alcoólica.

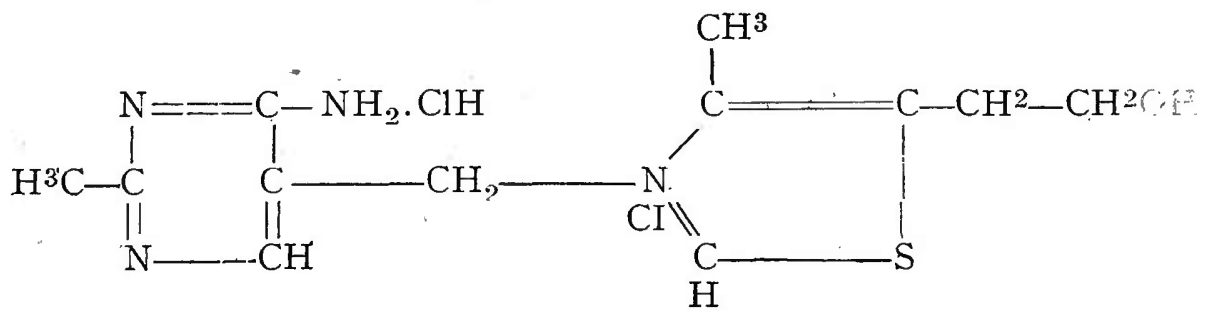

Cloreto de tiamina (B1)

Explica-se porisso a proporcionalidade entre a necessidade diária de vitamina $\mathrm{B} 1$ e a quota glicídica da diéta.<smiles></smiles>

A aloxana e sua fórma reduzida - o ácido dialúrico - constituem um dos sistemas de oxi-redução do orgạnismo.

A aloxana tomariả parte na desánimação dos amino-ácidos (2).<smiles>O=C1NC(=O)C(=O)N1</smiles>

Aloxana

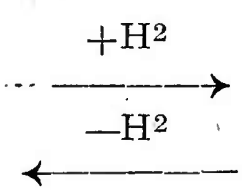

$\leftarrow$<smiles>O=C1NC(=O)C(O)C1=O</smiles>

Ácido dialúrico

O anel aloxânico está presente, porém, condensado a um grupo diaminobenzênico, na riboflavina e no fermento amarelo, do qual a vitamina flavínica é parte do grupo prostético (citoflavina).

A riboflavina e o fermento amarelo funcionam no organismo como transportadores intermediários de hidrogênio, nas reações de oxi-redução. À riboflavina entra na composição do grupo prostético de outros fermentos como a d-amino-ácido-oxidase, (3) a xantinooxidase (4) e a piridin-mucleótido-oxidase (5-6-7) (o núcleo prostético é o dinucléotido isoaloxazina-adenina). 


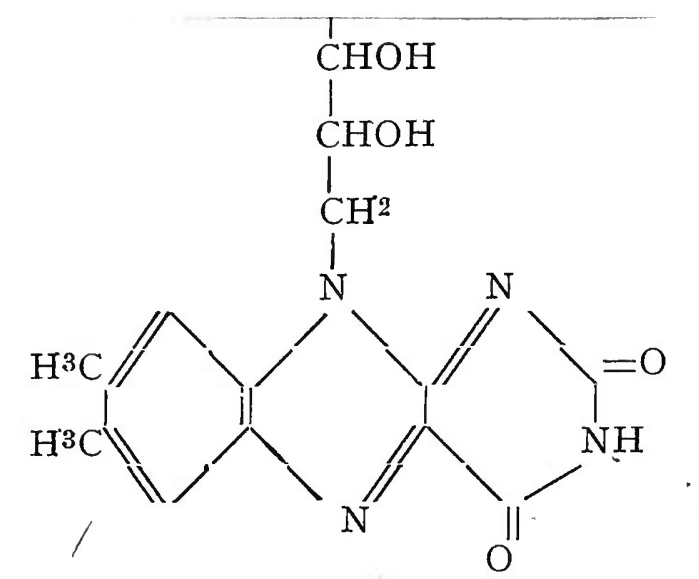

Riboflavina (6,7-dimetil-9-d-1'-ribitil-isoaloxazina)
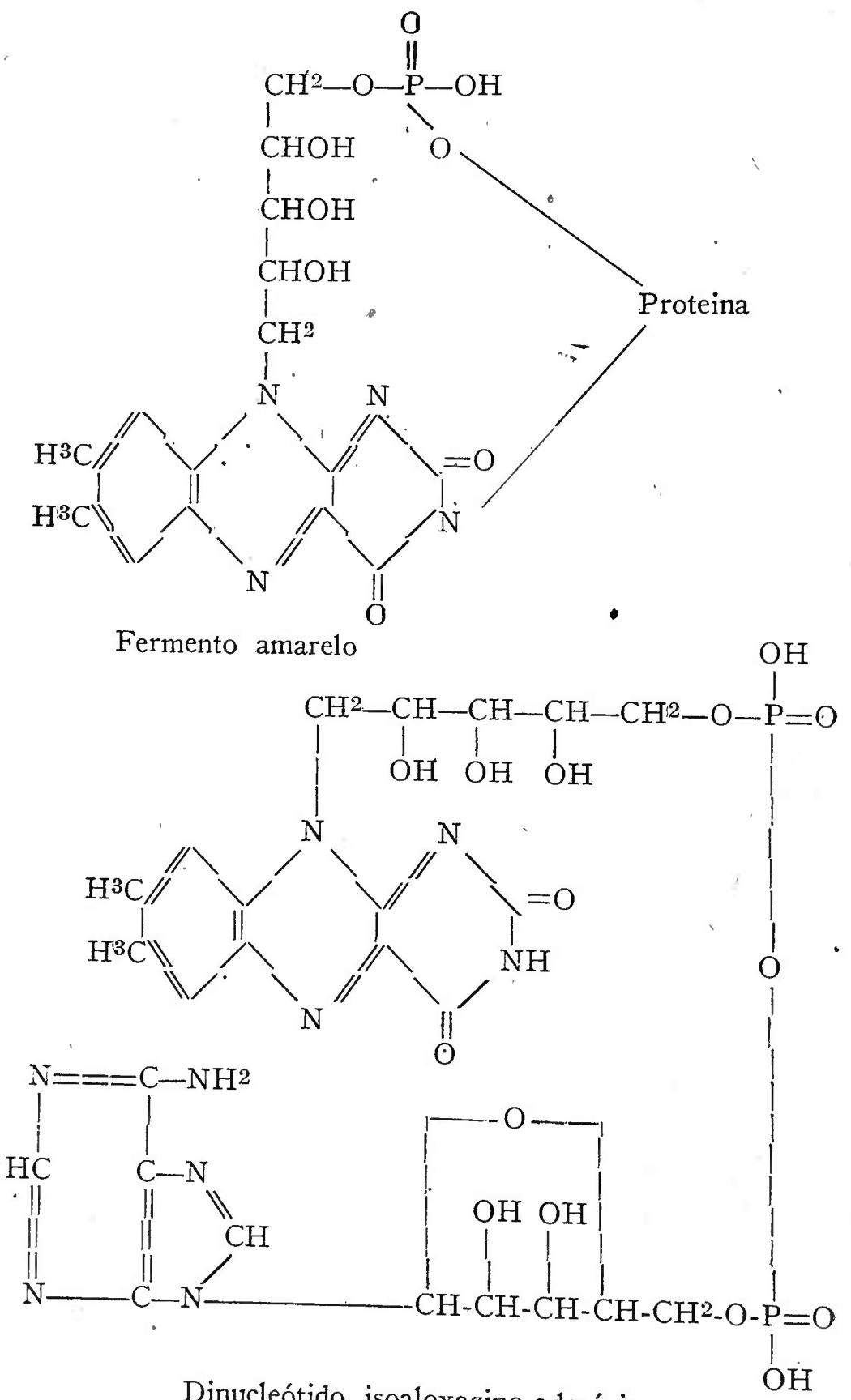
$\mathrm{O}$ anel pirimídico foi combinado à sulfanilamida, obtendo-se o composto 2-sulfanilamido-pirimidina, que se encontra no mercado (Sulfadiazina).

As bases que apresentam o anel purínico são: a adeninà (6-amino-purina) e a guanina (2-amino-6-oxi-purina).<smiles>C1=NC2=Nc3nc[nH]c3C2=N1</smiles>

Purina<smiles>NC1=NC2=c3[nH]cnc3=NC2=N1</smiles>

Adenina<smiles></smiles>

Guanina.

A purina foi sintetizada por EmIL FISCHER em 1899 e seu nome resulta da fusão dos dois termos da expressão "purum uricum".

A adenina, descoberta por KosSEL, recebeu essa denominação por ter sido obtida de uma glândula (pâncreas de boi).

A adenina faz parte do ácido adenilpirofosfórico cuja scisão hidrolítica exotérmica constitue o "primum movens" da contração muscular. Desta decomposição resultam o ácido adenílico (nucleótido) e o ácido fosfórico, destinando-se ește à fosforilação da molécula gylicídica.

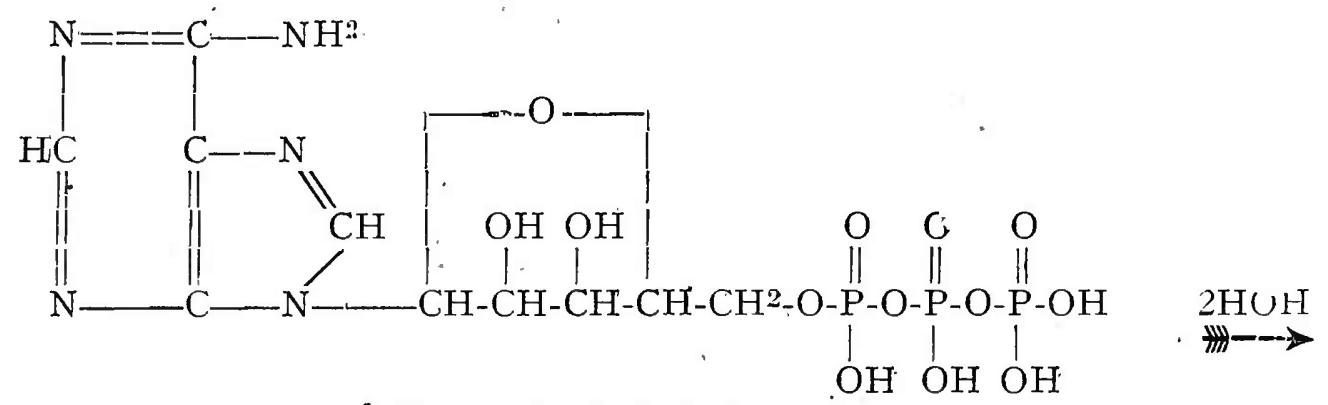

Áçido adenil-pirofosfórico

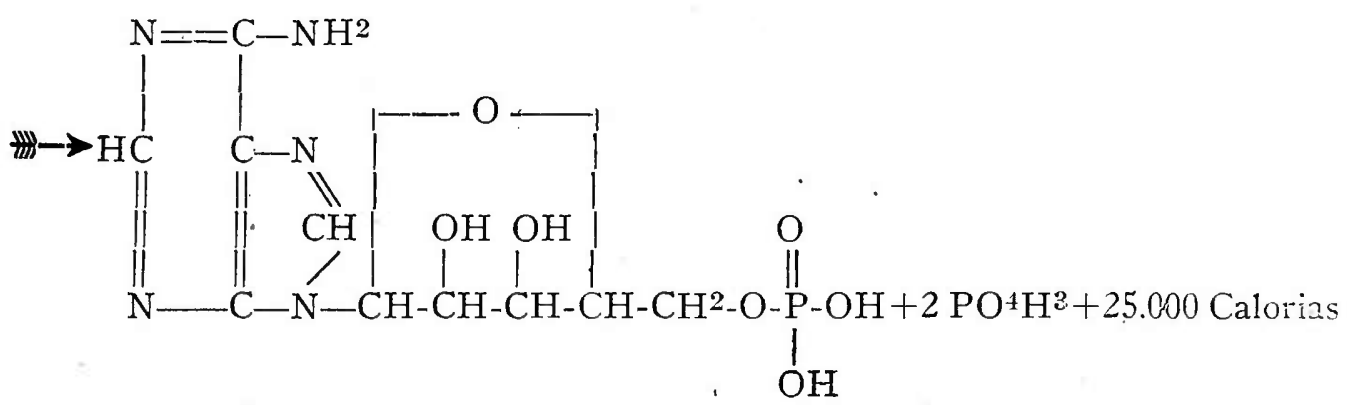

Ácido Adenílico

A mesma base púrica é encontrada em dois dinucleótidos de grande importância fisiológica - o coenzima I e o coenzima II núcleos prostéticos de dehidrogenases. Ambos funcionam como acepto- 
res de hidrogênio nas oxidações orgânicas, sendo indispensavel a sua presença na fermentação alcoólica e na glicolise dos tecidos.

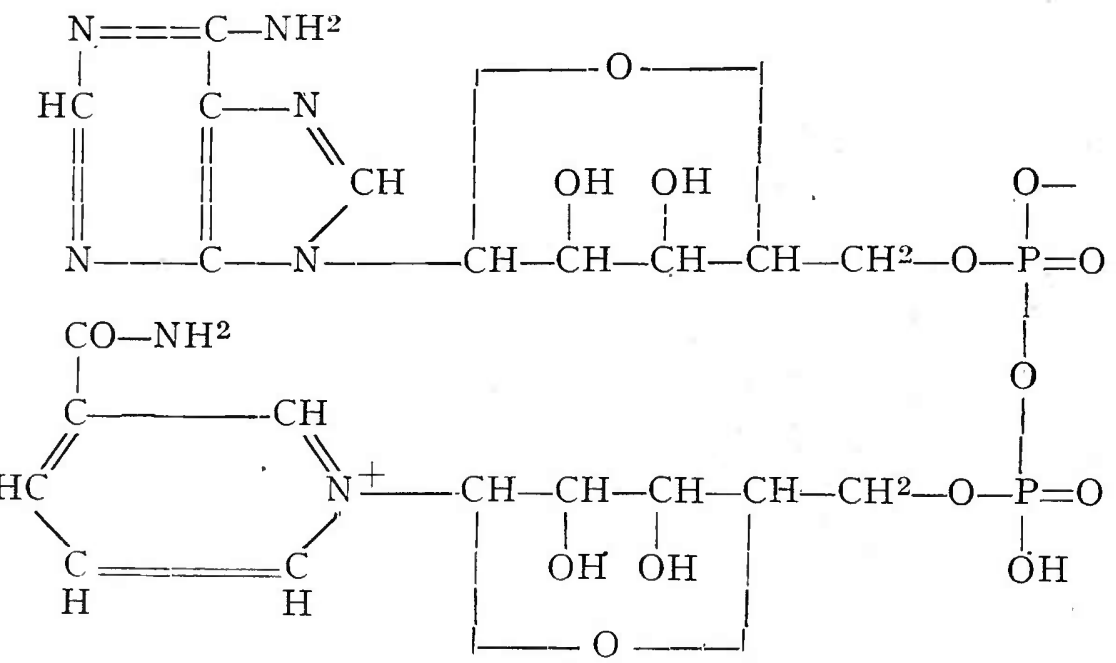

Coenzima I

O coenzima II difere do coenzima I por ter uma molécula mais de ácido fosfórico. Ambos possuem uma base azotada vitamínica a nicotinamida.

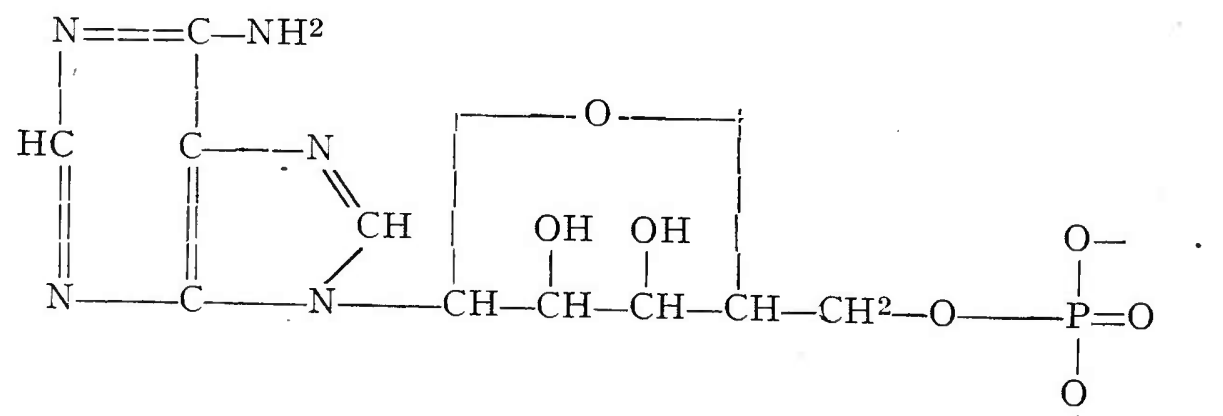<smiles>CP(=O)(O)OP(=O)(O)OCC(I)C(O)C(O)C(I)[N+]1C=CC=C(C(N)=O)C1</smiles>

Coenzima II (Cofermento de Warburg)

A guanina, assim chamada por ter sido isolada do guano, encontra-se nas escamas e na bexiga natatória dos peixes e é o agente bioquímico da "gota guanínica" dos porcos.

Uma configuração purínica semelhante à da guanina é encontrada numa subtância cujo estudo tem merecido muita atenção por 
estar intimamente relacionado com o problema das anemias em geral e talvez com o da anemia perniciosa.

Trata-se da xantopterina ou uropterina, pigmento amarelo existente nas azas e no tegumento de insetos (16), na urina (19) e em extratos de figado (20).

Em 1937 Tschesche e Wolf (21) mostraram a eficiência deste composto na cura da anemia por leite de cabra em ratos. O mesmo princípio cura a anemia nutricional de peixes (20).

Sua fórmula provavel, segundo Schöpf (18), é a seguinte:<smiles>N=C1NC2=NC(=CO)N=C1C2=O</smiles>

Xantopterina (2-imino-6-oxi-8-hidroximetileno-purina)

Por desanimação e oxidação, no organismo, a adenina se converte em hipoxantina, e a guanina em xantina, proseguindo o processo oxidativo até a faśe de ácido írico (mamíferos uricotélicos) ou, de alantoina (mamíferos alantoinotélicos).<smiles>Nc1ncnnc1N</smiles>

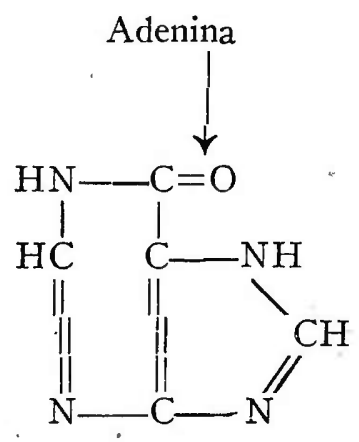

Hipoxantina<smiles>N[14c]1nc2nc[nH]c2c(=O)[nH]1</smiles><smiles>O=C(NC(=O)c1cccnc1)Nc1ccncn1</smiles>

Xantina<smiles></smiles>

Alantoina

Ácido úrico 
A hipoxantina é encontrada na inosina e no ácido inosinico, que aparecem no metabolismo muscular.

A xantina, encontrada raramente en cálculos urinários, aumenta a ação bacteriostática das sulfonamidas (23) e constitue o princípio antitóxico isolado do figado por Neale e Winter (22), o qual exerce ação protetora contra o clorofórmio e o tetracloreto de carbono.

Certos derivados xantínicos como a cafeina, a teobromina e a tcofilina, têm larga aplicação terapêutica.

A cafeina é estimulante do centro respiratório e das funções secretórias e possue tambem ação vasodilatadora.

A teobromina tem ação vaso-dilatadora e por aumentar o fluxosanguíneo renal, exerce forte ação diứética.

A teofilina tambem é vaso-dilatadora, especialmente das artérias coronárias.<smiles>CCCCCCCCCCCCC</smiles>

(1-3-dimetil-xantina)<smiles>Cn1cnc2c1c(=O)[nH]c(=O)n2C</smiles>

Teobromina

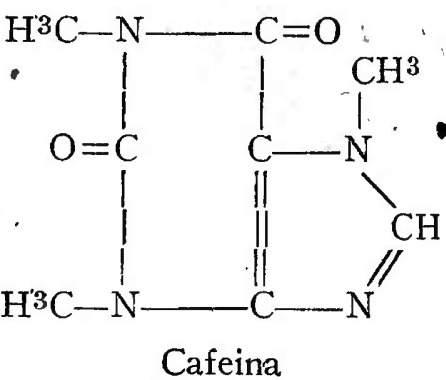

(3-7-dimetil-xantina)

(1-3-7-trimetil-xantina)

$\mathrm{O}$ ácido úrico, produto final característico do metabolismo nucleoproteídico do homem e macacos antropoides, é a substância química envolvida no tão estudado processo da gota.

A alantoina, termo final do metabolismo nucleoproteídico da maioria dos mamíferos foi utilizada no tratamènto das osteomielites depois que se-verificou agirem as larvas de moscas por seu intermédio. Hoje emprega-se a uréia com melhores resultados e talvez seja a ação terapêutica da alántoina, neste caso, devida à presença de uma cadeia urêica na sua molécula.

$\mathrm{Na}$ elucidação da constituição dos ácidos nucleicos colaboraram intensamente Kossel, Levene, Jones, Perkins e outros.

Ficou, após longos estudos, definitivamente assentada a seguinte constituição. $O$ ácido fosfórico liga-se estericamente à ribose ou ribodesose, e esta, osidicamente à base púrica ou pirimídica, resultando uma tríade que recebeu o nome de nucleótido. adenílico.

Existem nucleótidos em liberdade como, por exemplo, o ácido

Os ácidos nucleicos são sempre polinucleótidos, em géral tetranucleótidos. como os ácidos nucleicos omais conhecidos, isto é, o ácido timo-nucleico e o ácido nucleico do levedo. Recentemente isolaram do pâncreas penta e hexanucleótidos. No ácido nucleico os nucleótidos estariam unidos por uma ligação
tipo ester entre o ácido fosfórico de un e a ose do seguinte. Para o
ácido nucleico do levedo teriamos então a ácido nucleico do levedo teriamos então a seguinte estrutura: 


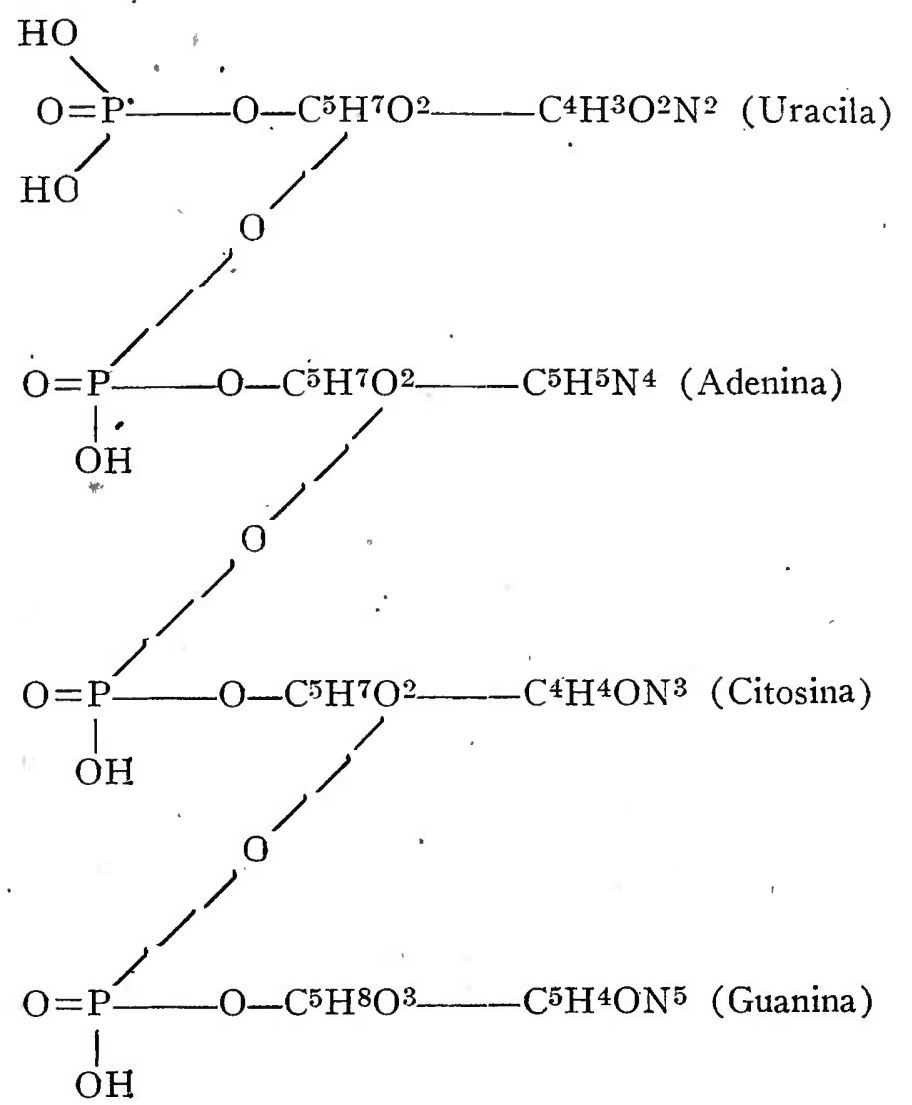

Ácido nucleiço do levédo (Tetranucleótido)

- Pela ação de nucleinases ou de álcalis é possivel romper as ligações internucleotídicas e obter assim os nucleótidos que podem depois ser convenientemente isolados por precipitação com sais de chumbo (8).

Desde que Jackson Jr., Parker Jr., Rinehart e Taylor (9), em 1931, demonstraram clinicamente a eficiência dos nucleótidos no tratamento das agranulocitoses, larga messe de trabalhos foi publicada em todo o mundo, confirmando, de modo geral, a referida.propriedade destes derivados nucleínicos.

O adenilato ferroso (nucleotidato) foi empregado com sucesso no tratamento das anemias, visto o nucleótido excitar a medula óssea (10).

No tratamento das neutropenias em geral, o primeiro preparado farmacêtutico foi o "Pentnucleotide", (Smith, Cline \& French Laboratories, Philadelphia, U. S. A.) de renome mundial, que logo foi tentado por laboratórios europeus, aparecendo o "Nucleid" (12) na França e o "Nucleotrat" (13) na Alemanha.

Segundo as verificações de Frost e Elvehjem (11), em 1937, ratos submetidos a dietas isentas do fator $\mathrm{W}$, mas suplementadas com nucleótidos adenínicos e nicotinamida, oferecem uma apreciavel resposta de crescimento, o que faz entrever a possibilidade de os derivados nucleoproteídicos aparecerem na estrutura de mais um fator vitamínico. 
Us nucleóticlos são passíveis tambem de uṇa scisão hidrolítica entre a molécula do ácido fosfórico e a da ose, resultando um procluto constituido da ose ligada à base púrica ou pirimídica. Tal procluto, verdadeiro heterósido, recebe o nome de nucleósido.

Os nucléosidos tambem tiveram aplicação terapêutica. Entre eles assinalamos o adenilribósido (adenosina), que possue ação estimulante da leucopoiese, tal como os nucleótidos, e uma ação vascular, dilatando as arterias coronárias, pelo que é empregado no tratamento da "angina pectoris".

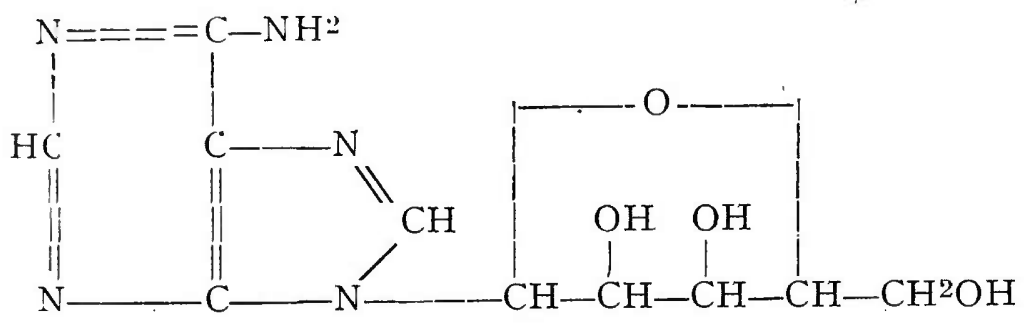

Adenosina

$\cup$ proprio ácido nucleico, sob a forma de sal de sódió é largamente utilizado como leucocitogênico e antitérmico, melhorando as defezàs do organismo (14).

De um modo geral, o ácido nucleico e seus derivados (nucleótidos e nucleósidos) são vasodilatadores e consequentemente hipotensores, têm ação hematopoiética, inhibem as contrações intestinais e estimulam a musculatura uterina.

De todos os derivados nucleínicos, o ácido adenílico e a adenosina se mostraram mais eficazes (15).

\section{BIBLIOGRAFIA}

(1) Warburg, O. e Christian, W. - Ueber ein neues Oxydationsfermęnt und sein Absorptionsspektrum: Biochem, Z., 1932 - 254, 438/58.

(1a) Jones, W. e Perkins, M. E. - The nitrogenous groups of plant nucleic acid. J: Biol. Chem., 1924/25, 62, 557.

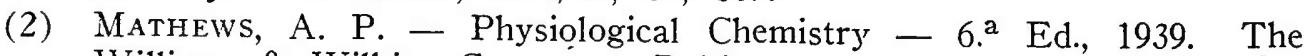
Williams \& Wilkins Company. Baltimore.

(3) Krebs, H. A. - Klin. Wochschr., 1932, 11, 1744 e Z. physiol. Chem., 1933, 217 - 191 (Citado em 17).

(4) Ball, E. G. - Science, 1938, 88, 131 e J. Biol. Chem., 1938, 128, 51 (Citado em 17).

(5) Warburg, O. e Christian, W. - Biochem. Z., 1938, 298, 368 (Citado

(6) HaAs, E. - Biochem. Z., 1938, 298, 378 (Citado em 17).

(7) Corran, H. S., Green, D. E. e Straub, F. B. - Biochem. J., 1939, 33, 793 (Citado em 17).

(8) Jones, W. e Perkins, M. E. - The nucleotides formed by the action of boiled pancreas on yeast nucleic acid. J. Biol. Chem., 1923, 55, 557/65.

(9) Jackson JR. H., Parker Jr. F., Rinehart, J. F. e Taylor, F. H. L. - Studies of diseases of the lymphoid and myeloid tissues. VI - The 
treatment of malignant neutropenia, with pentose nucleotides. J.A.M.A. 1931, 97, 1936/40.

(10) Ruskin, S. L. e Katz, E. - Ann. Internal Med., 1936, 9, 1549/60.

(11) Frost, D. V. e Elvehjem, C. A. - Further studies on factor W. J. Biol. Chem., 1937, 121, 255/73.

(12) Grenet, H., IsaAc-Georges, P. e Hamelle, C. - Angine avec agranulocitose. Traitment par les nucleotides pentosiques. Bull. et Mém. Soc. Med. Hôp. Paris, 1939, 55 (8), 417/21.

(13) Jenn, W. - Pentoșenucleotid (Nucleotrat) und Thrombozyten. Deut. med. Wochschr., 1935-61-1555/6.

(14) Patriarca, M. - Rass. Clin. terap. sci. affini, 1938, 37, 119/26.

(15) Drury, A. N. - The physiological activity of nucleic acid and its derivatives. Physiol. Rev., 1936, 16, 292/325.

(16) Harrow, B. - Textbook of Biochemistry - 2. a Ed., W. B. Saunders Company. Philádelphia, 1941.

(17) Allen, F. W. - The biochemistry of the nucleic acids, purines and pyrimidines. Ann. Rev. Biochem., 1941, 10, 221/44.

(18) ScHöpp, C. - The constitution of leucopterin and xanthopterin. Naturwissench., 1940, 28, 478/9 (Citado em C. A. 1941; 35 (10) - 3233²).

(19) Koschara, W. - Z. physiol: Chem., 1937, 240, 127 (Citado em 20).

(20) Simmons, R. W. e Norris, E. R. - Xanthopterin, the fish anemia factor. J. Biol. Chem., 1941, 140 (2), 679/80.

(21) Tschesche, R. e Wolf, H. J. - Z. physiol. Chem., 1937, 248, 34 (Citado em 20).

(22) Neale, R. C. e Winter, H. C. - The identification of the active crystalline substance from liver. wich protects against liver damage due to chloroform and carbon tetrachloride, and a study of related compounds. J. Pharm. Exp. Therap., 1938, 62, 127.

(23) Harris, J. S. e KoHN; H.'I. - The effect of purines on the action of sulfonamides. J. Biol. Chem., 1941, 141, (3), 989/90.

\section{Preparados Farmacêticos}

Temos a venda Marcas e Formulas licenciadas e incumbimo-nos de sua compra, venda, ov reristro. LTCENCIAMOS FORMULAS, PODENDO SER EXAMINADAS POR NOSSO TECNICO FARMACEUTICO OU FQRNECER FORMULAS.

Legalizamos Laboratorios Farmaceuticos, fazemos quaisquer contratos, de instalação, de exploração, de propaganda, de fabricação

C O N S U L T E M - N O S S E M C O M P R O M I S S O

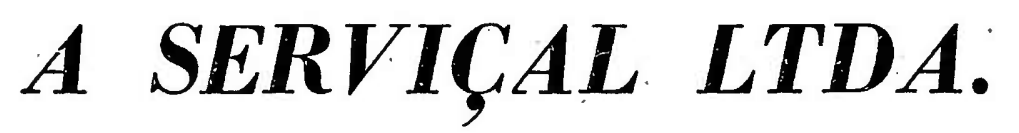

agencias reunidas rio de Janeiro $E$ S. PaUlo Diretor Geral : ROMEU RODRIGUES

Marcas - Patentes e Licenças de Preparados Farmacêuticos Comestiveis - Bebidas - Etc.

R I O D E J A N E I R O

Rua da Quitanda, 7 - Sob.

(Perto da Rua S. José)

CAIXA POSTAL, 3384
Nosso lema: Servir, sem nos servir, dos clientes
$\begin{array}{llllllll}\mathbf{S} & \tilde{A} & \mathbf{O} & \mathbf{P} & \mathbf{A} & \mathbf{U} & \mathbf{L} & \mathbf{O}\end{array}$ Rua Direita, 64 $-3 .^{\circ}$ And. CAIXAS POSTAIS $\begin{array}{llllll}3631 & 1421\end{array}$ 


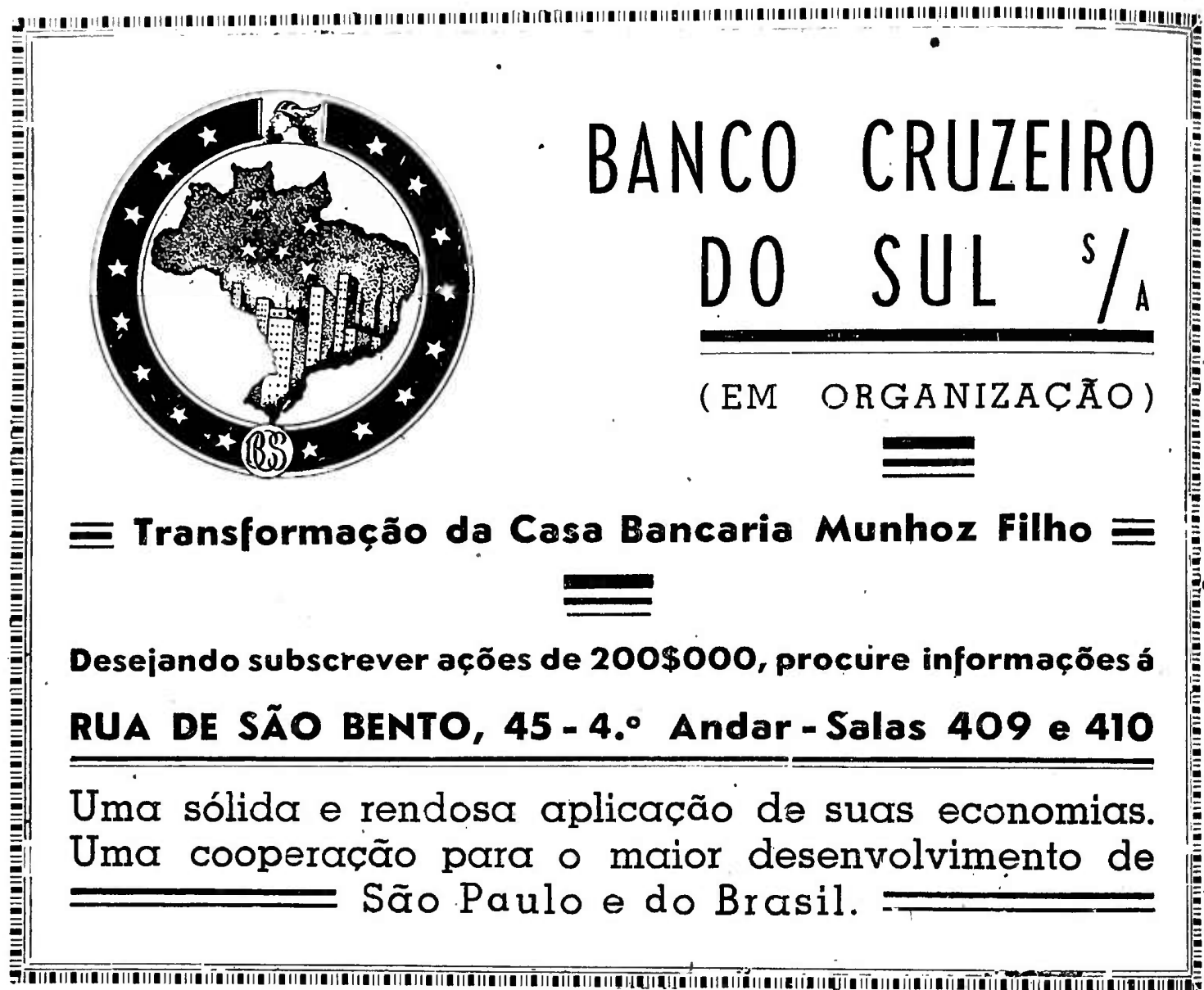

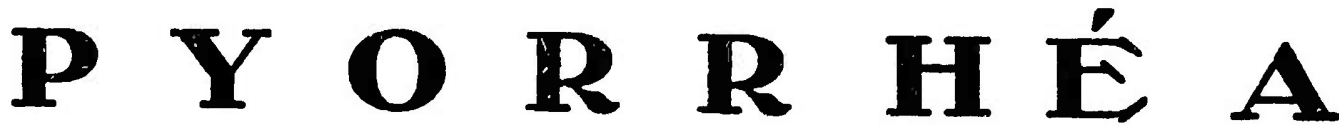

Gengivas sangrentas, dentes abalados e mau halito: Resultados positivos em 8 dias, com o especifico

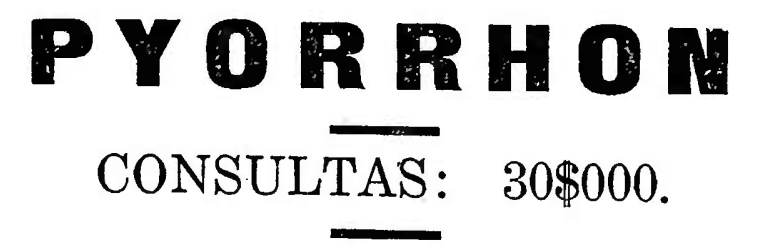

DEMOṄSTRAÇõES PRATICAS AOS SENHORES MEDICOS E DENTISTAS

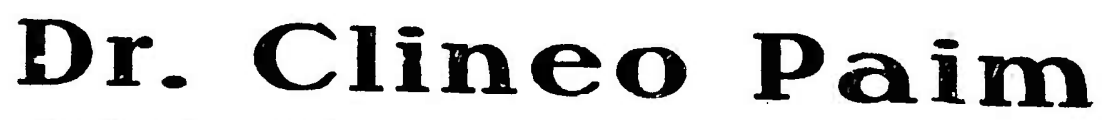

R. Barão de Itapetininga, $120-5 .^{\circ}$ andar - Salas, 505 e 506 (CASA GUATAPARÁ)

TELEFONE: 4-4050 - SÃO PAULO 